\title{
A clinical and histochemical study of cholestasis ${ }^{1}$
}

\author{
V. J. DESMET, A.-M. BULlENS, AND J. DE GROOTE
}

From the Laboratorium voor Histochemie en Cytochemie, Dienst voor Pathologische Ontleedkunde B, and the Kliniek voor Inwendige Ziekten, Academisch Ziekenhuis St. Rafaël, Leuven, Belgium

SUMMARY A histochemical study of conjugated and total bilirubin was made on liver biopsies of 150 patients. Three types of cholestasis were defined: type I, characterized by the presence of intracellular pigment granules in the hepatocytes; type II, showing intracellular granules and extracellular thrombi (this group may be subdivided according to the eventual presence of coarse pigment deposits in the parenchymal cells); and type III, showing intracellular granules, extracellular thrombi, and also bile pigment in the Kupffer cells. The fine liver cell granules correspond mainly to conjugated bilirubin, whereas the coarse deposits usually contain unconjugated pigment. The extracellular thrombi mostly contain conjugated bilirubin; the Kupffer cell pigment is predominantly of the unconjugated type. In cholestasis types II and III a diffuse directly reacting pigment is also observed. The finding of unconjugated pigment in different locations and the eventual deconjugation by $\beta$-glucuronidase is discussed. A correlation was found between the different types of cholestasis, the level of bilirubinaemia, and its dynamic evolution. This suggests that the proposed types of cholestasis may represent successive stages of increasing cholestasis. The type of cholestasis and the nature of the pigment are largely independent of the aetiology.

It is shown that a large percentage of minor degrees of cholestasis is missed when only conventional histological methods are used.

The mechanisms by which morphological cholestasis is brought about are discussed in the light of the present findings.

According to its etymology cholestasis means stasis of bile. Although this definition seems very simple, the pathological conditions it describes are still surrounded by problems and hypotheses. General agreement on a suitable definition is still lacking. This was recently emphasized in an excellent review of the subject (Popper, 1968). Haemmerli (1966) stressed a double meaning for the term cholestasis: a clinical functional one and a histological one. According to the first interpretation cholestasis represents a syndrome with icterus, pruritus, and elevation of the serum

${ }^{1}$ This work was supported by a grant from the Fonds voor Wetenschappelijk Geneeskundig Onderzoek van België.

Received for publication 9 December 1969. alkaline phosphatase level and often of the serum lipids and cholesterol. The pathologist, however, $\stackrel{\varrho}{\subset}$ describes cholestasis as the appearance of visible $\mathbb{D}$ bile pigments in a microscopic preparation of $\stackrel{+}{+}$ liver tissue. Unless otherwise specified, the term cholestasis in this study will be used in its histo- $\frac{O}{\mathbb{D}}$ logical meaning, referring to a microscopically $\stackrel{\odot}{\odot}$ visible bilirubin accumulation in the liver tissue, $\stackrel{\mathbb{Q}}{\varrho}$ demonstrable with the techniques used in the present work, irrespective of its aetiology and 8 accompanying pathology.

Until now, no available method for the histological identification of bilirubin in tissue sections allowed a selective differentiation between the conjugated and unconjugated forms of bilirubin. 
Recently, it has been demonstrated (Van Roy and Heirwegh, 1968) that the diazonium salt of ethylanthranilate reacts specifically with conjugated bilirubin, even in the presence of a large excess of unconjugated bilirubin. This diazonium salt proved to be of value for the histochemical demonstration of conjugated bilirubin in tissue sections (Desmet, Bullens, de Groote, and Heirwegh, 1968). At the same time a method was developed (Raia, 1967) for the demonstration of total bilirubin with the diazonium salt of 2,4dichloraniline. These methods, used in parallel, allow a new approach for a more specific and detailed histochemical investigation of the precise nature of bile pigment accumulations in cholestatic liver tissue.

\section{Materials and Methods}

PATIENTS

A series of 150 patients with different forms of liver pathology was studied (see Table III). The ultimate diagnosis was reached taking into account all available data, including clinical features as well as technical investigations such as biochemical analyses, laparoscopy, and liver puncture biopsy. Chronic hepatitis was classified according to de Groote, Desmet, Gedigk, Korb, Popper, Poulsen, Scheuer, Schmid, Thaler, Uehlinger, and Wepler (1968). Chronic persistent hepatitis and nonspecific reactive hepatitis were grouped together because of their similar histological pictures. No differentiation was made between alcoholic and non-alcoholic cirrhosis, since patients with alcoholic cirrhosis constituted a small minority in this study (one case in 18), and this correlates with the overall proportion in the Academisch Ziekenhuis where $82 \%$ of cirrhotic patients had non-alcoholic cirrhosis in the period 1964 to 1968 . Those cases in which fatty change was the predominant or the single pathological feature were classified as steatosis cases; the degree of steatosis was usually mild. No distinction was made between viral hepatitis and presumed drug hepatitis, although it is agreed that the aetiology may be totally different. Less frequent forms of liver pathology were grouped under the heading 'various', and will be discussed separately.

\section{TECHNIQUES}

A liver puncture or surgical biopsy was obtained from all these 150 patients. The tissue was fixed in cold formol-calcium (Baker, 1946). The main part of the biopsy was routinely processed by paraffin embedding. Sections were stained with haematoxylin and eosin, periodic acid Schiff after $\alpha$-amylase digestion, Schmorl's reaction for lipofuscin, Perls's reaction for iron, and Hall's technique for bilirubin (Pearse, 1960). A small part of the biopsy was reserved for frozen sections. In order to study the deposition of specific types of bile pigment, serial frozen sections were examined with the following techniques respectively: (1) the diazonium salt of ethylanthranilate for conjugated bilirubin (Desmet et al, 1968); (2) the diazonium salt of 2,4-dichloraniline for total bilirubin (Raia, 1967); (3) Fouchet's reagent for total bilirubin (Hall, 1960); and (4) examination in ultraviolet light for lipofuscins (yellow fluorescence).

\section{Results and Comment}

TYPES OF CHOLESTASIS

In order to correlate more effectively the microscopic findings with the clinical data, it seemed useful to establish a classification of different types of cholestasis.

Type $\mathbf{O}$ comprises those cases without visible bile pigment, ie, no cholestasis. A case was classified as type $I$ as soon as a minimal amount of bilirubin granules could be demonstrated in the liver cells by any of the methods used in this study. Of the 57 cases grouped under types I and II, 22 (19 of type I and three of type II) showed a negative bilirubin staining on paraffin sections. These cases would have been classified as type $\mathbf{O}$ if only routine techniques had been used, but pigment granules, and in three cases even thrombi, were visualized in the frozen sections of the same biopsies. Even if allowance had been made for differences due to tissue sampling, this finding points towards a significant loss of bile pigment during routine histological procedures for embedding tissues and staining sections. In all cases examined more bilirubin was visualized in the frozen sections than in the paraffin preparations.

Cholestasis type II is characterized by the simultaneous occurrence of both intercellular thrombi and intracellular pigment deposits. As mentioned above, in three cases out of 25 bilirubin was demonstrated in the frozen sections only. The pigment in the hepatocytic cytopiasm was not only found in the form of the granules similar to those of cholestasis type I, but also in the form of coarse granules or blocs in 15 cases (type II B). There seems to be some ground for considering these cases as a separate subgroup, as suggested by the results of specific staining of conjugated and unconjugated bilirubin and the correlation with the serum bilirubinaemia. Since, however, the distinction between 'fine' and 'coarse' granules is subjective and not completely reliable, a definite separation of this subgroup is difficult, although it may be relevant. Throughout this study type IIA cholestasis will include those cases where the intracellular pigment is seen only in 'fine' granules. 


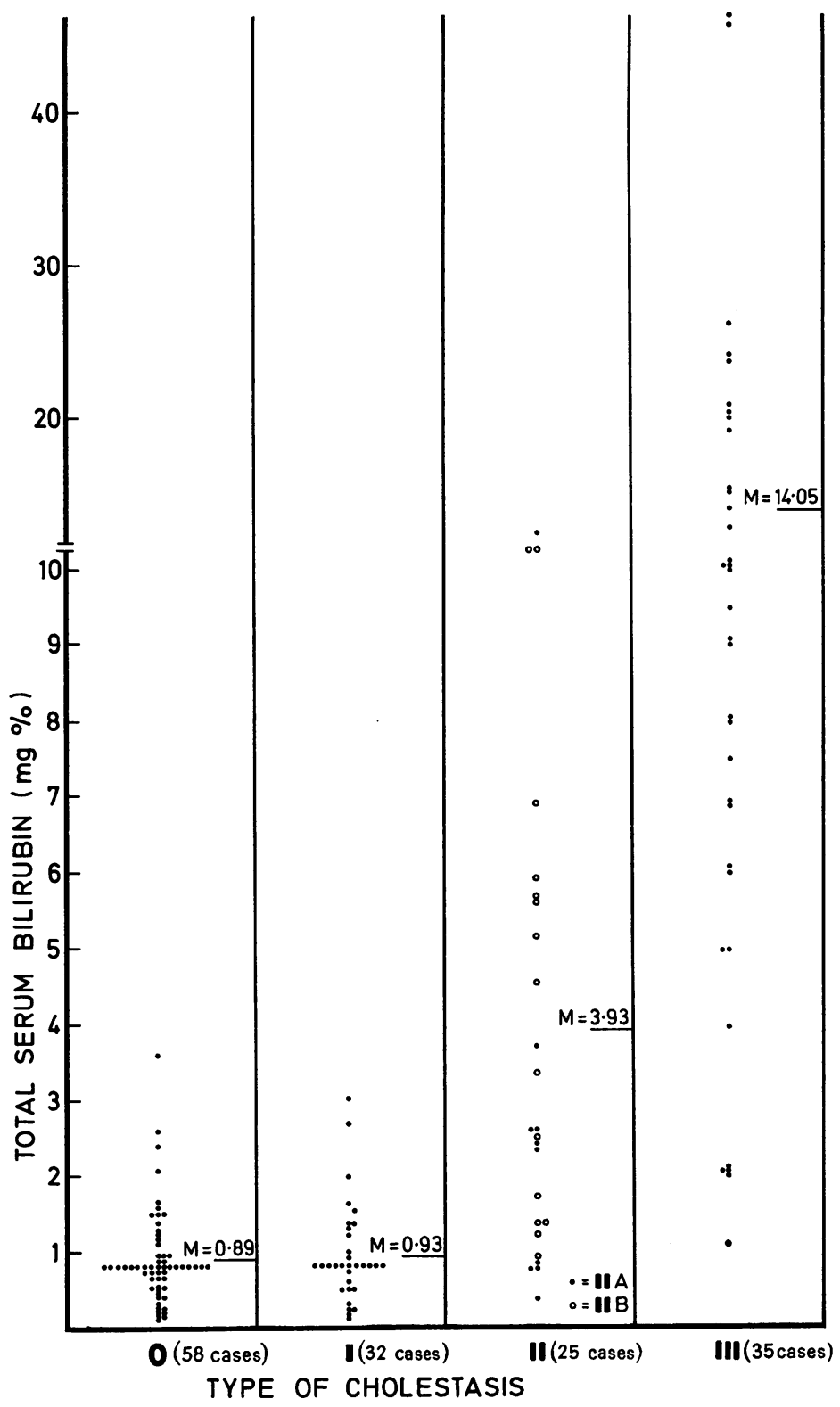

Cholestasis type III was diagnosed when in addition to intra- and extracellular pigment deposits, bile pigments could also be seen within the Kupffer cells and/or macrophages.

In liver biopsies where a certain degree of cholestasis was apparent, bile pigment was also $\stackrel{5}{?}$ found as a diffuse cytoplasmic impregnation of the liver cells in the cholestatic areas. This was usually the case in type II and mostly in type III. The diffuse pigment can only be demonstrated with the newer diazonium techniques on frozen is sections, for it seems to be washed out during the routine histological procedures (Desmet et al, 1968).

In this classification of histological cholestasis other criteria, such as bile infarcts or the presence of bile accretions in ductules and ducts, were not taken into account. The zonal distribution of the $\dot{\sigma}$ cholestasis in the liver lobules was centrolobular or in the vast majority of the cases except in cases $\vec{\sigma}$ of neonatal hepatitis. Although this classification $\frac{\rho}{3}$ was not primarily intended to represent a quan- $\overrightarrow{ }$ titative gradation, an overall correlation exists $\subseteq$ between the total amount of pigment deposited $\widetilde{\sigma}$ in the liver and the different types of cholestasis. $\vec{\bullet}$

CORRELATION BETWEEN TYPE OF CHOLESTASIS AND BIOCHEMICAL PARAMETERS

In order to corroborate the visual impression that the different types of cholestasis roughly correspond to a quantitative gradation, the correlation between the type of cholestasis and the bilirubinaemia was studied. The Figure shows the serum bilirubin values plotted against the different histological types of cholestasis and Table I summarizes the statistical evaluation of these findings.

The differences in mean serum bilirubin levels $\delta$ are statistically significant between the cholestasis $₹$ types I and II and types II and III, though it $\mathrm{O}$ appears that the mean serum bilirubin level is nearly identical in types $\mathrm{O}$ and $\mathrm{I}$. This indicates

Fig. Correlation between morphological cholestasis and serum bilirubin levels.

\begin{tabular}{|c|c|c|c|c|}
\hline Type of Cholestasis & $\begin{array}{l}\text { Number of } \\
\text { Patients }\end{array}$ & $\begin{array}{l}\text { Mean Serum Bilirubin } \\
\text { Values }(\mathrm{mg} / 100 \mathrm{ml})\end{array}$ & Standard Deviation & Results of $t$ Test \\
\hline $\mathbf{O}$ & 58 & 0.89 & 0.6 & \}$_{P}>0.05$ \\
\hline I & 32 & 0.93 & 0.8 & \\
\hline II & 25 & 3.93 & 3.45 & $\mathbf{P}<0.001$ \\
\hline $\mathbf{A}$ & 10 & 2.91 & $3 \cdot 5$ & \\
\hline B & 15 & $4 \cdot 61$ & $3 \cdot 3$ & $P<0.001$ \\
\hline III & 35 & $14 \cdot 05$ & 11 & \\
\hline
\end{tabular}

Table I Statistical analysis of the differences in mean serum bilirubinaemia between the different types of cholestasis 


$\left.\left.\left.\left.\begin{array}{lllll}\hline \text { Bilirubinaemia } & \begin{array}{l}\text { Number of } \\ \text { Patients }\end{array} & \begin{array}{l}\text { Mean Serum Bilirubin } \\ \text { Level }(\mathrm{mg} / 100 \mathrm{ml})\end{array} & \begin{array}{l}\text { Standard } \\ \text { Deviation }\end{array} & \text { Results of } t \text { Test } \\ \hline \text { Increasing } & 7 & 20.59 & 13.34 \\ \text { Stable } & 19 & 13.64 & 7.67 \\ \text { Decreasing } & 9 & 6.93 & 5.35\end{array}\right\} \mathbf{0 . 0 5 > P > 0 . 0 2 5}\right\}\right\} \geqslant 0.05\right\} P>0.05$

Table II Statistical analysis of the differences in mean bilirubinaemia in the patients with cholestasis type III related to the evolution of the bilirubinaemia

\begin{tabular}{|c|c|c|c|c|c|}
\hline \multirow[t]{2}{*}{ Final Diagnosis } & \multicolumn{4}{|c|}{ Type of Cholestasis } & \multirow[t]{2}{*}{ Total } \\
\hline & $O$ & $I$ & $I I(A$ and $B)$ & III & \\
\hline Acute hepatitis & & & 12 & 17 & 29 \\
\hline Chronic persistent hepatitis & 9 & 8 & & & 17 \\
\hline $\begin{array}{l}\text { Chronic aggressive } \\
\text { hepatitis A }\end{array}$ & & & & & \\
\hline $\begin{array}{l}\text { hepatitis A } \\
\text { Cirrhosis }\end{array}$ & 10 & & & & 10 \\
\hline $\begin{array}{l}\text { Cirrhosis } \\
\text { Extralobular obstruction }\end{array}$ & 8 & $\begin{array}{l}3 \\
6\end{array}$ & $\begin{array}{l}4 \\
6\end{array}$ & $\begin{array}{r}3 \\
12\end{array}$ & $\begin{array}{l}18 \\
24\end{array}$ \\
\hline Steatosis & 6 & 4 & 1 & & 11 \\
\hline Various & 13 & 11 & 2 & 3 & 29 \\
\hline 'Normal' liver & 12 & & & & $\begin{array}{r}12 \\
150\end{array}$ \\
\hline
\end{tabular}

Table III Correlation between the type of cholestasis and the final diagnosis

that apart from normal serum bilirubinaemia, a slight accumulation of fine bilirubin granules may be present in the hepatocytes. Although the differences between the types I, II, and III are statistically significant, the high values for the standard deviation, and the overlapping values for bilirubin (Fig.) suggest that factors other than mere hyperbilirubinaemia may interfere in distinguishing the respective histological types of cholestasis.

Four cases with abnormal serum bilirubin levels above $2 \mathrm{mg} \%$ are classified in group $\mathrm{O}$ (Fig.). The differential serum bilirubin determination showed a low proportion of direct reacting bilirubin in these cases, the ratio of conjugated bilirubin to total bilirubin being $11.9 \%$, $44 \%, 57 \%$, and $52 \%$ respectively. Although the difference in mean serum bilirubin level is not statistically significant between the two subgroups of type II, it remains an interesting observation that the mean bilirubinaemia is higher in those 15 cases (IIB) in which coarse intracellular pigment granules were observed in the liver cells.

The patients of group III were subdivided into three categories, according to whether their bilirubinaemia at the time of liver biopsy was in an increasing phase, at a constant level, or in a declining phase (Table II). In this way, it can be shown that, for the same type of cholestasis, the mean level in the group with an increasing phase of bilirubinaemia is higher than in the groups with stable or decreasing phases.

No correlation could be found between the histological type of cholestasis and other biochemical parameters, such as the serum alkaline phosphatase level, the thymol turbidity test, the zinc sulphate flocculation test, and the serum levels of SGOT and SGPT transaminases.

\section{NATURE OF ACCUMULATED BILE PIGMENT IN CHOLESTASIS}

The application of specific staining techniques for both conjugated and total bilirubin, completed with other methods for identifying lipofuscin on serial frozen sections, allowed a study of the nature of the pigment deposited at different sites in cholestatic liver tissue. The fine granules in the parenchymal cells usually showed the staining characteristics of conjugated bilirubin, whereas the coarse granules more often corresponded to unconjugated bile pigment. Both types may be admixed to lipofuscin. In most intercellular thrombi the pigment reacted as conjugated bilirubin. Some thrombi, however, stained partly or totally as unconjugated bilirubin. The bile pigment present in the Kupffer cells most usually corresponded to unconjugated bilirubin, also often admixed to lipofuscin although some granules contained conjugated pigment. The diffuse pigment, impregnating the whole cytoplasm of liver cells in the cholestatic areas, mainly corresponded to conjugated bilirubin.

\section{CORRELATION BETWEEN TYPE OF}

\section{CHOLESTASIS AND FINAL DIAGNOSIS}

As shown in Table III, no type of cholestasis is typical for any kind of diagnosis. All cases of acute hepatitis studied showed some cholestasis of at least type II. Cases of chronic hepatitis, especially chronic aggressive hepatitis, showed much less or even no cholestasis. Extralobular obstruction (Krstulović, van Damme, and Desmet, 1968), almost by definition, showed some degree of histological cholestasis, which may vary in amount and in appearance according to the duration of the obstruction of the bile flow. All types of cholestasis were observed in the category 'various'. Eleven cases in type I were found with no primary liver disease; they had a normal direct bilirubinaemia and only occasionally a slight abnormality in one of the liver function tests. Type II includes one case with Hodgkin infiltration in the liver and one case of periar- 
teritis nodosa with hepatic involvement. The cases in type III include two children with neonatal giant cell hepatitis and one obscure case of intrahepatic cholestasis possibly of toxic origin.

No definite conclusions can be drawn about the occurrence and the type of cholestasis in different forms of liver pathology, since these results depend to a large extent on the overall selection of the patients for hospital admission and for liver puncture biopsy.

\section{Discussion}

As already stated, the term cholestasis may be interpreted in different ways. Even when used in the purely histological sense, one has to be conscious of the fact that the amount of bile pigment visualized in a given tissue section depends to a large extent on the histological methods applied. The histochemical procedures using diazonium salts on frozen sections are more reliable for demonstrating small amounts of bile pigment than the oxidation procedures applied on paraffin sections. Indeed, 19 cases out of 32 of type I cholestasis and three cases out of 25 of type II cholestasis would have been missed if only paraffin sections-even with specific bilirubin staining - had been used. A certain amount of bile pigment can be eluted from the tissue during the routine processing for histological embedding and staining. The importance of the mode of tissue preparation has already been stressed (Biava, 1964; Nolte, 1966; Desmet et al, 1968) and seems to be particularly important in cases with slight or minimal cholestasis.

Several authors (Dubin, 1959; Mallory, 1947; Weinbren, 1952) reported their visual impression that serum bilirubinaemia and liver cholestasis are related. In the present study a significant correlation was found between the different types of cholestasis and the mean serum bilirubinaemia of the patients in each group. This finding confirms the visual impression that the types of cholestasis roughly coincide with a quantitative gradation. The occasional discrepancy between a given histological picture and the serum bilirubin level at the time of the biopsy indicates that other important factors are also involved, such as the duration of the jaundice and its dynamic evolution. This is clearly shown in the patients of group III. In this group a noticeable difference for the same histological type of cholestasis was found in the mean serum bilirubinaemia, depending whether the serum bilirubin was in a rising phase, at a constant level, or in a declining phase. This finding confirms the known observation (Popper, 1968) that the bilirubin level in the serum may vary more rapidly than the visible accumulation of pigment in the liver.
Besides these dynamic factors, the ratio of conjugated to total serum bilirubin must also be considered in order to correlate effectively the histological cholestasis and the serum bilirubinaemia. In four patients with abnormal serum $\stackrel{?}{\Rightarrow}$ bilirubin no cholestasis was observed (type 0 ), but there was a low ratio. In a previous study this? was shown not to be due to hepatocellular damage 음 or obstruction (Fevery, Claes, Heirwegh, and de $\frac{\bar{c}}{\frac{\sigma}{\sigma}}$ Groote, 1967).

The mean bilirubinaemia of the group with intracellular cholestasis only (type $I$ ) is very similar to that of patients without cholestasis (type O). This might be expected to be due to a $\vec{\omega}$ previously higher serum bilirubin level. However, $\stackrel{\circ}{\circ}$ this was not the case for any of the patients with type I cholestasis. Thus a slight accumulation of intracellular pigment granules in patients with $\vec{\sigma}$ normal bilirubinaemia may occur even before an or increase in the serum bilirubin level is observed; $\vec{\sigma}$ this means that in the early period of a cholestatic 은 episode the serum bilirubin lags behind the first accumulation of bile pigment in the liver tissue. $\subseteq$ This observation, although surprising at first $\stackrel{D}{\circ}$ sight, may be important in the pathogenesis of $\overrightarrow{0}$ cholestasis. According to several authors (Billing, Williams, and Richards, 1964; Barrett, Berk, Menken, and Berlin, 1968) the plasma bilirubin disappearance curve takes the form of the sum of two exponential functions. This suggests the existence on the one hand of a dynamic $\frac{\otimes}{\otimes}$ equilibrium between two pools containing bilirubin and, on the other hand, a site where, under $\overline{\overrightarrow{ }}$ normal circumstances, bilirubin is irreversibly $\exists$ cleared. The plasma may act as one pool, the liver cells as the second pool, and the intrahepatic biliary tree as the irreversible clearance $\frac{Q}{C}$ way. The ability of the liver cell to handle bili- $\vec{\sigma}$ rubin may be expressed as storage capacity and transport maximum (Wheeler, Meltzer, and Bradley, 1960). Under normal conditions no $\frac{3}{3}$ bilirubin pigment is visible in the liver tissue under the microscope, because the irreversible clearance mechanism is adequate. When, how- $\frac{D}{O}$ ever, for some pathological reason this mechanism is disturbed, the total clearance capacity of $\mathrm{N}$ the liver will be reduced leading to an accumula- $N$ tion of bilirubin in the liver pool. When this accumulation exceeds the storage capacity bilirubin will be precipitated in the liver cell

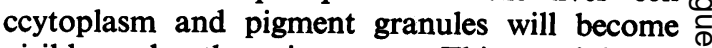
visible under the microscope. This precipitated $\stackrel{9}{?}$ pigment probably represents relatively inert 0 bilirubin which does not take an active part in the rapid exchange between liver cell, plasma $\mathbb{D}$ pool, and excretion. These granules may be con- $\mathbb{\mathbb { D }}$ sidered as some sort of pathological storage capacity of the liver cell. When bilirubin continues to accumulate in the liver pool it re- $\delta$ gurgitates in increasing amounts towards the plasma pool and precipitates further as visible 흥 pigment in the cytoplasm. This accumulation of bilirubin and also of other bile constituents may 
eventually damage the liver cell. The slow behaviour of precipitated pigment may explain why in a decreasing phase of bilirubinaemia the disappearance from the liver tissue lags behind the disappearance from the blood.

A subclassification was attempted in group II on the basis of the eventual presence of coarse pigment granules in the liver cells. Although it is agreed that the interpretation of 'coarse' intracellular granules in frozen sections may be subjective, the results obtained indicate that there may be some grounds for this subdivision. The application of specific histochemical methods for conjugated and total bilirubin shows that the great majority of coarse granules contain unconjugated bile pigment in contrast to the smaller pigment deposits which usually stain as conjugated bilirubin. Moreover, there is a difference in the mean serum bilirubinaemia of the subgroups of type II cholestasis, the bilirubin level being higher in group IIB (coarse granules). This information is useful for a better insight into the morphogenesis of cholestasis.

The application of specific histochemical techniques allows the identification in different sites of the nature of the pigment deposits: diffuse cytoplasmic impregnation, cytoplasmic granules and intercellular thrombi. The pigment which is responsible for the diffuse cytoplasmic staining of the parenchymal cells in advanced cholestasis corresponds to conjugated bilirubin. Its diffuse aspect suggests a localization in a widespread cytoplasmic compartment, such as the endoplasmic reticulum or the cell sap. The rather pronounced affinity of bilirubin glucuronide for cell sap as compared to cell particles (Heirwegh, van Roy, and de Groote, 1964; Bernstein, Essner, Gartner, and Arias, 1966) would favour the latter hypothesis. This diffuse pigment may represent the visible overload of conjugated bilirubin in the liver cells by a lack of excretion with reversed transport across the cell to the sinusoidal pole. Determination in vitro of the activity of bilirubin glucuronyltransferase also demonstrates that the capacity of the liver to process incoming bilirubin is sufficient in cases of cholestasis, although the enzyme activity per gram liver weight may be somewhat reduced (Metge, Owen, Foulk, and Hoffman, 1964). The present finding seems to demonstrate at the cellular level that the conjugating capacity of the liver cells is not arrested by cessation of bile flow, but may continue for a considerable time.

Small granules containing bilirubin in parenchymal cells mostly reacted as conjugated bilirubin, whereas coarse granules usually contain unconjugated pigment. The precise intracellular localization of these granules has not been definitely established (Orlandi, 1962; Biava, 1964). According to some authors (Orlandi, 1962; Essner and Novikoff, 1960), bile pigment may accumulate in lysosomes or fused masses of these organelles. Hydrolysis of conjugated bilirubin by the action of $\beta$-glucuronidase could then explain the presence of granular unconjugated bilirubin. This would also correlate with the predominance of unconjugated pigment in Kupffer cells which are known to contain more and bigger lysosomes. On the other hand, in a detailed electron-microscopic study of pigment deposition in cholestatic liver tissue (Biava, 1964), bile pigment granules were shown to consist of precipitated ground cytoplasm and some fragmented agranular membranes, considered to be the result of a particular type of focal degeneration. These cytoplasmic clumps are at first not surrounded by a membranous envelope. If this turns out to be the predominant form of the granular intracellular bile pigment accumulation, the intriguing problem remains whether this focal cytoplasmic degeneration could be directly due to the overload by conjugated or unconjugated bilirubin, or indeed be due to both. A few pigment granules did not stain for bilirubin at all, but reacted as lipofuscin, which also accumulates in cholestatic liver tissue.

Some extracellular thrombi did not react as conjugated bilirubin. As the liver is known to excrete only conjugated bilirubin (Billing, Cole, and Lathe, 1957) possible hydrolysis of the conjugated pigments accumulating in the canaliculi could be invoked to explain this phenomenon. It is conceivable that parenchymal cells adjacent to bile plugs suffer from biliary intoxication and release their lysosomal enzymes. Alternatively the lack of staining as conjugated pigment might be explained by an alteration in the reactivity of the bile pigment impregnating the rather densely packed cytoplasmic material present in the bile plugs, shown to consist of precipitated pericanalicular ectoplasm and canalicular membranes (Biava, 1964). This last hypothesis could also explain the negative reaction of some cytoplasmic bilirubin-containing granules and might even account for the negative reaction of some thrombi when stained for total bilirubin with the diazonium salt of 2,4-dichloraniline. The eventual role of $\beta$-glucuronidase in the formation of granular material containing unconjugated bilirubin is under investigation.

The nature of the pigment deposited in a particular site is essentially the same in all forms of cholestasis, irrespective of their aetiology. This means that the specific histochemical staining of bile pigments is not helpful in the differential diagnosis of the aetiology of cholestasis.

The overall results of this study allow some further insight into the still highly hypothetical mechanisms by which morphological cholestasis is brought about. Because of the correlation between the different types of cholestasis and the mean bilirubinaemia of the respective groups, it may be assumed that morphological cholestasis proceeds in time and in degree from type $I$ to type III. In the early period of impairment of the secretory function of the liver cell by whatever 
cause, conjugated bilirubin is sequestrated in the form of small granules in the liver cell even before a significant rise in the serum bilirubin level occurs. This precipitated pigment may be considered to be relatively inert and less readily exchangeable, thus representing some sort of pathological 'extra' storage capacity of the liver cell. Further ultrastructural study is needed to explore its precise subcellular localization.

With the continuing disturbance of liver-cell secretion, bile pigment not only further precipitates in the cytoplasm but also regurgitates towards the plasma pool, as reflected by increasing levels of serum bilirubin. At this stage coarse pigment granules are found in addition to an increasing amount of finer deposits. The unconjugated nature of the bilirubin present in the coarse granules suggests that these deposits are older pigment conglomerates, already attacked by lysosomal $\beta$-glucuronidase. It is reasonable to assume that the earliest fine deposits become surrounded by membranes and incorporated into so-called autophagic vacuoles or secondary lysosomes (Biava, 1964; Barone, Carrozza, and Inferrera, 1968). At this stage a deconjugation of already conjugated bilirubin may occur (Raia, 1967), together with accumulation of lipofuscin pigment, derived from degenerated membranous material.

An increase in liver $\beta$-glucuronidase has been reported in cholestatic liver tissue (Acocella, Tenconi, and Armas-Merino, 1968; Sussi and Rubatelli, 1968; Billing, Raia, and ArmasMerino, 1968) and can be demonstrated histochemically (unpublished observations). At this stage of type II cholestasis, extracellular deposits are also characteristically found. They contain mainly conjugated bilirubin. The unconjugated pigment found in some of them may represent deconjugated bilirubin, resulting from the release of lysosomal $\beta$-glucuronidase from the surrounding damaged hepatocytes. These deposits are usually interpreted as thrombi of inspissated bile in dilated canaliculi. Recent electron-microscopical work (Oledzka-Slotwinska, and Desmet, 1969) showed, however, that these extracellular deposits are not always in a canalicular location, but may be found in dilated sinusoidal recesses. In this location, they may represent segregated areas of degenerated cytoplasm impregnated with bile pigment and extruded from the rest of the cell (Oledzka-Slotwinska and Desmet, 1968 and 1969). The precise mechanism by which these intercellular thrombi are formed, preferentially in centrolobular location, is not yet clear. The increasing accumulation of bilirubin (and surely other bile constituents as well) in and outside the liver cells has a damaging effect, histologically described as 'feathery degeneration' (Popper and Schaffner, 1967; Gall and Dobrogorsky, 1964). This parenchymal damage triggers a proliferative and hyperplastic reaction of the Kupffer cells, which become macrophages. These cells have been shown to contain numerous and large organelles of the lysosome group (Essner and Novikoff, 1961) and $\Omega$ show strong positive reactions in histochemical preparations for acid phosphatase and $\beta-\vec{F}$ glucuronidase.

The phagocytic engulfment of parenchymal? cell debris, pigment granules, and thrombi leads $\frac{\overline{\bar{N}}}{\mathrm{c}}$ to the accumulation of bilirubin associated with $\frac{\vec{\sigma}}{\sigma}$ lipofuscin in the Kupffer cells. This feature is $\varrho$ characteristic of type III cholestasis. The observa- $ڤ$ tion that the bilirubin in the Kupffer cells is $\vec{\circ}$ mainly of the unconjugated type can be explained by the deconjugating role of lysosomal $\beta-\vec{\omega}$ glucuronidase. If pigment accumulates in the $\stackrel{\circ}{\varrho}$ liver tissue takes place along these lines, it $\subsetneq$ becomes clear that the histological picture is not $\vec{\partial}$ primarily influenced by the aetiological agent, $\dot{\sigma}$ but to a much higher extent by the degree of bile $\stackrel{\sigma}{\rightarrow}$ pigment accumulated in the liver pool, the velocity with which this occurs, its duration, and $\frac{\text { ? }}{2}$ dynamic evolution. Daily diagnostic difficulties $\overrightarrow{\vec{c}}$ in the histological differential diagnosis of intra- $\frac{\varsigma}{\sigma}$ and extralobular cholestasis confirm this point $\overparen{\Phi}$ of view.

The authors wish to express their appreciation to Drs C. De Wolf-Peeters and B. van Damme for helpful discussions, to Dr B. van Damme for the statistical work; to Miss R. Gillard, Mrs M. J. De Craen- $\frac{\circ}{D}$ Verrycken, and Miss L. Tanghe for technical assist- $\varrho$ ance, and to Mrs P. Vanderwegen-Mahy for typing $\overline{\bar{O}}$ the manuscript.

\section{References}

Acocella, G., Tenconi, L. T., and Armas-Merino, R. (1968). Does deconjugation of bilirubin glucuronide occur in obstructive jaundice? Lancet, 1, 68-69.

Baker, J. R. (1946). The histochemical recognition of lipine. Quart. J. micr. Sci., 87, 441-470.

Barone, P., Carrozza, G., and Inferrera, C. (1968). Bile morphology in cholestasis. Acta hepato-splenol. (Stuttg.), 15, 389- 음 399.

Barrett, P., Berk, P. D., Menken, M., and Berlin, N. I. (1968). D Bilirubin turnover studies in normal and pathologic states using Bilirubin $-{ }^{14} \mathrm{C}$. Ann. intern. Med., 68, 355-377.

Bernstein, L. H., Essner, J. B., Gartner, L., and Arias, I. M. (1966). N Hepatic intracellular distribution of tritium-labeled unconjugated and conjugated bilirubin in normal and Gunn $\mathrm{N}$ rats. J. clin. Invest., 45, 1194-1201.

Biava, C. (1964). Studies on cholestasis. The fine structure and $\omega$ morphogenesis of hepatocellular and canalicular bile $\sigma$ pigment. Lab. Invest., 13, 1099-1123.

Billing, B. H., Cole, P. G., and Lathe, G. H. (1957). The excretion of bilirubin as a diglucuronide giving the direct Van den $\mathbb{D}$ Bergh reaction. Biochem. J., 65, 774-784.

Billing, B. H., Williams, R., and Richards, T. G. (1964). Defects in hepatic transport of bilirubin in congenital hyperbilirubinemia: an analysis of plasma bilirubin disappearance curves. Clin. Sci., 27, 245-257.

Billing, B. H., Raia, S., and Armas-Merino, R. (1968). The origin of unconjugated bilirubin in the liver in obstructive

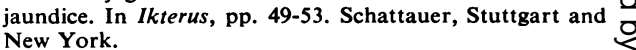

de Groote, J., Desmet, V. J., Gedigk, P., Korb, G., Popper, H., Poulsen, H., Scheuer, P. J., Schmid, M., Thaler, H., O Uehlinger, R., and Wepler. W. (1968). A classification of chronic hepatitis. Lancet, 2, 626-628.

Desmet, V. J., Bullens, A. M., de Groote, J., and Heirwegh, K. P. M. (1968). A new diazo reagent for specific staining of conjugated bilirubin in tissue sections. J. Histochem. Cytochem., 16, 419-427. 
Dubin, I. N. (1959). Intrahepatic bile stasis in acute nonfatal viral hepatitis; its incidence, pathogenesis, and correlation with jaundice. Gastroenterology, 36, 645-660.

Essner, E., and Novikoff, A. B. (1960). Human hepatocellular pigments and lysosomes. J. Ultrastruct. Res., 3, 374-391.

Essner, E., and Novikoff, A. B. (1961). Localization of acid phosphatase activity in hepatic lysosomes by means of electron microscopy. J. biophys, biochem. Cytol., 9, 773-784.

Fevery, J., Claes, J., Heirwegh, K., and de Groote, J. (1967) Hyperbilirubinemia. Significance of the ratio between direct-reacting and total bilirubin. Clin. chim. Acta, 17, 73-79.

Gall, E. A., and Dobrogorsky, I. O. (1964). Hepatic alterations in obstructive jaundice. Amer. J. clin. Path., 41, 126-139.

Haemmerli, P. (1966). Jaundice during pregnancy Acta med. scand. Suppl. 444.

Hall, M. J. (1960). A staining reaction for bilirubin in sections of tissues. Amer. J. clin. Path., 34, 313-316.

Heirwegh, K., Van Roy, F., and De Groote, J. (1964). Distribution of bilirubin and bilirubin glucuronide over cell fractions. T. Gastro-ent., 7, 184-187.

Krstulović, B., Damme, Van B., and Desmet, V. J. (1968). Comparative histochemical study of rat liver in bile-duct ligation and in alpha-naphthyl isothiocyanate (ANIT) intoxication. Amer. J. Path., 52, 423-436.

Mallory, T. B. (1947). The pathology of epidemic hepatitis. $J$. Amer. med. Ass., 134, 655-662.

Metge, W. R., Owen, Ch. A., Foulk, W. T., and Hoffman, H. N. (1964). Bilirubin glucuronyltransferase activity in liver disease. J. Lab. clin. Med., 64, 89-98.

Nolte, D. (1966). Ikterus der Leber bei chronischer Herzinsuffizienz. Virchows Arch. path. Anat., 341, 37-42.

Oledzka-Slotwinska, H., and Desmet, V. (1968). Ultracyto- chemical study of parenchymal liver cell necrosis in conditions of extrahepatic cholestasis. Abstracts: Fourth European Regional Conference on Electron Microscopy, Rome: $483-484$.

Oledzka-Slotwinska, H., and Desmet, V. (1969). Participation of the cell membrane in the formation of 'autophagic vacuoles'. Virchows Arch. Abt. B, 2, 47-61.

Orlandi, F. (1962). Electron microscopic observations on human liver during cholestasis. Acta hepato-splenol. (Stuttg.), 9, 155-164.

Pearse, A. G. E. (1960). Histochemistry, Theoretical and Applied. Churchill, London.

Popper, H. (1968). Cholestasis. Ann. Rev. Med., 19, 39-56.

Popper, H., and Schaffner, F. (1957). Liver: Structure and Function. McGraw-Hill, New York-Toronto-London.

Raia, S. (1967a). Histochemical demonstration of conjugated and unconjugated bilirubin in cholestatic liver tissue. In Bilirubin Metabolism, pp. 285-289. Blackwell, Oxford.

Raia, S. (1967b). Histochemistry of bile pigments in the cholestatic liver, with special reference to its correlation with lysosomal $\beta$-glucuronidase. Ph.D. Thesis, London. Quoted in B. H Billing et al (1968).

Roy, Van F., and Heirwegh, K. P. M. (1968). Determination of bilirubin gluucronide and assay of glucuronyltransferase with bilirubin as acceptor. Biochem. J., 107, 507-518.

Sussi, P. L., and Rubaltelli, F. F. (1968). $\beta$-glucuronidase activity in cholestatic liver. Lancet, 1, 1396-1397.

Weinbren, K. (1952). The pathology of hepatitis. J. Path. Bact. 64, 395-413.

Wheeler, H. O., Meltzer, J. I., and Bradley, S. E. (1960). Biliary transport and hepatic storage of sulfobromphtalein sodium in the unanesthetized dog, in normal man, and in patients with hepatic disease. J. clin. Invest., 39, 1131-1144. 